\title{
Preliminary Design and Validation of a 3D-Printed Continuously Variable Transmission for an Electric Vehicle Prototype ${ }^{\dagger}$
}

\author{
Marcos R. C. Coimbra ${ }^{1}$, Társis P. Barbosa ${ }^{1}(\mathbb{D})$ and César M. A. Vasques ${ }^{2, *(\mathbb{D})}$ \\ 1 Department of Telecommunications Engineering and Mechatronics, Federal University of São João del-Rei, \\ Alto Paraopeba Campus, Rodovia MG 443, km 7, Ouro Branco 36420-00, MG, Brazil; \\ mrafaelcc@live.com (M.R.C.C.); tarsisbarbosa@ufsj.edu.br (T.P.B.) \\ 2 proMetheus, Escola Superior de Tecnologia e Gestão, Instituto Politécnico de Viana do Castelo, Rua Escola \\ Industrial e Comercial de Nun'Álvares, 4900-347 Viana do Castelo, Portugal \\ * Correspondence: cmavasques@gmail.com \\ + Presented at the 2nd International Electronic Conference on Applied Sciences, 15-31 October 2021; Available \\ online: https://asec2021.sciforum.net/.
}

check for updates

Citation: Coimbra, M.R.C.; Barbosa, T.P.; Vasques, C.M.A. Preliminary Design and Validation of a 3D-Printed Continuously Variable Transmission for an Electric Vehicle Prototype. Eng. Proc. 2021, 11, 11. https://doi.org/10.3390/ASEC202111178

Academic Editor: Filippo Berto

Published: 15 October 2021

Publisher's Note: MDPI stays neutral with regard to jurisdictional claims in published maps and institutional affiliations.

Copyright: (c) 2021 by the authors. Licensee MDPI, Basel, Switzerland. This article is an open access article distributed under the terms and conditions of the Creative Commons Attribution (CC BY) license (https:// creativecommons.org/licenses/by/ $4.0 /)$.

\begin{abstract}
This article discusses the progress made in developing a new 3D-printed continuously variable transmission (CVT) for an electric vehicle (EV) prototype competing in the Shell Ecomarathon electric battery category, a global energy efficiency competition sponsored by Shell. The proposed system is composed of a polymeric conic gear assembled in the motor axle and directly coupled to the rear tire of the vehicle. The conical shape allows to implement a continuous variation of the gear diameter in contact with the tire. The motor with the gear was mounted over a board with linear bearings, allowing the speed ratio to change by moving the board laterally. A 3D-printing slicing software with an optimization algorithm plug-in was used to determine the best printing parameters for the conic gear based on the tangential force, maximum displacement and safety factor. When compared to the original part with a $100 \%$ infill density, the optimized solution reduced the component mass by about $12 \%$ while maintaining safe mechanical resistance and stiffness.
\end{abstract}

Keywords: continuously variable transmission; powertrain design; electric vehicle; 3D printing; Shell Eco-marathon

\section{Introduction}

The automotive industry has been heavily reliant on the use of fossil fuels for decades. However, due to rising diesel and gasoline prices, as well as environmental pollution and fossil fuel depletion, it was concluded that alternate vehicle propulsion methods were required. Electric vehicles (EVs) have been intensively studied and appear as a possible solution for reducing global warming emission gases in this scenario. To put it in perspective, the transportation industry alone accounts for over $30 \%$ of global warming emissions in the United States; thus, switching to electric vehicles would be a very responsible and environmentally sound option [1]. International conferences, such as the United Nations Framework Convention on Climate Change (UNFCCC), also show international pressure for the development of sustainable technologies. According to Miyamoto [2], the Kyoto Protocol, which was signed in 1997, had an indirect impact on climate change discussion by boosting the number of worldwide patent applications for renewable energy, emphasizing the need for international cooperation on the subject.

The Shell Group sponsors an international competition called the Shell Eco-marathon, which focuses on lowering vehicle fuel consumption and is competed in by university groups of enthusiastic automobile teachers and students all over the world [3-8]. This and similar events foster several automotive technology developments, including the demonstration of distinctive car designs, energy management systems, powertrain innovations, advanced use of materials and manufacturing methods, mechanical design and the development of new 3D-printed automotive parts [9-14]. A continuously variable transmission 
(CVT) provides a continuous range of gear ratios between predetermined limits, improving a vehicle's fuel economy and dynamic performance by better matching engine operating conditions to variable driving circumstances [15].

Additive manufacturing and 3D printing technologies are rapidly changing machinery engineering as we know it, allowing for more creativity and freedom in machine design innovation, with numerous advantages over traditional manufacturing [16]. Free and widely distributed computer-aided design (CAD) and manufacturing (CAM) software tools, as well as well-established computer numerical control (CNC) standards, combined with readily available and affordable commercial 3D printers and materials, are fueling an increase in the number of users and potential applications of these technologies, including powertrain and other automotive components $[17,18]$. While almost anyone with a basic understanding of 3D modeling and printing can create their own self-made parts and devices, the wide design freedom in terms of geometry and materials, as well as professional quality assurance, raises a slew of new complex engineering questions and scientific uncertainties that go beyond basic design and functionality. Due to the design and manufacturing versatility of 3D printing, as well as continuous change and evolution in the range of available materials, the development and application of 3D-printed powertrain components is still in its infancy, but research and development activities underway promise alternative feasible and breakthrough solutions.

In response to society's desire for efficient and environmentally friendly small automotive vehicles, this study proposes to design and validate a new 3D-printed CVT enabling improved powertrain efficiency with a simpler, lighter and cheaper design than existing options for EV prototypes. The competition and EV prototype's essential specifications are presented first, with the main requirements for transmission design identified, followed by the required engineering calculations and analysis. Following that, information about the 3D-printing technologies used is presented, as well as the analysis and results obtained from the optimized printing parameters for CVT gear manufacturing. Finally, the most important findings and conclusions are summarized.

\section{Materials and Methods}

At the Shell Eco-marathon, prototype vehicles must complete a $12 \mathrm{~km}$ circuit in less than $28 \mathrm{~min}$, which equates to 10 turns on the circuit depicted in Figure 1. As a result, an average speed of $25.71 \mathrm{~km} / \mathrm{h}$ is required to complete the circuit without exceeding the time limit. Normally, the circuit's speed limit is set between 0 and $35 \mathrm{~km} / \mathrm{h}$.
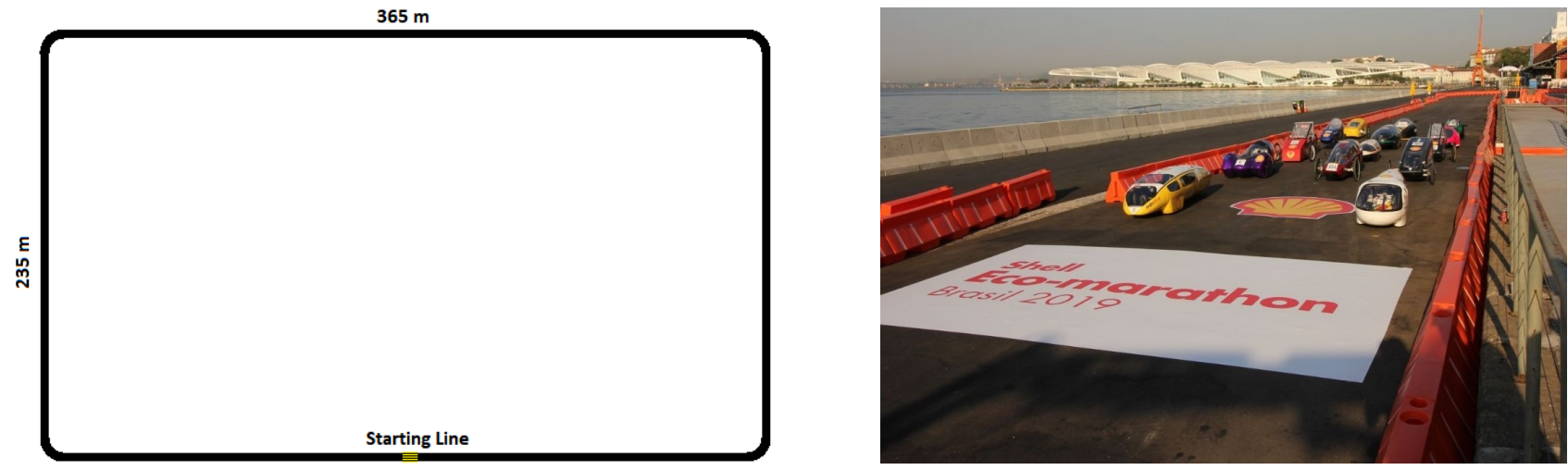

Figure 1. Circuit diagram and image of the Brazilian start line for the Shell Eco-marathon competition (5 m wide rectangular circuit with $90^{\circ}$ curves with an $8 \mathrm{~m}$ radius).

The energy consumption unit, commonly used for conventional vehicles with internal combustion engines (ICE), is a physical unit of fuel volume per unit distance, such as liters per $100 \mathrm{~km}(1 / 100 \mathrm{~km})$. In the case of EVs, energy consumption is evaluated in $\mathrm{kWh}$ per unit distance in $\mathrm{km}(\mathrm{kWh} / \mathrm{km})$ [19]. At the Shell Eco-marathon, the most energyefficient vehicle that wins the competition is the one that completes the entire circuit in the 
allotted time while consuming the least amount of energy - fuel, in the case of ICE vehicles, or battery, in the case of EVs. The vehicle's output speed is affected by the motor's input speed, the transmission speed ratio and the tire diameter. For simplicity, the prototype EV transmission system was first idealized with a fixed speed ratio in which a gear was directly connected to the tire of the rear wheel tire, eliminating the need for gear shifting and the construction and implementation of a more complex driveline system. In this architecture, when the throttle is pressed by the pilot, signals are sent to the motor controller to change the motor speed and, consequently, the wheel rotation. In the case of DC electric motors, the speed range can vary from zero to thousands of rotations per minute (rpm) depending on the voltage received from the motor controller. The first gear prototype design is shown in Figure 2a. This component was 3D printed and assembled in a prototype vehicle in order to validate the reliability of a plastic gear in the vehicle's powertrain. However, this solution harmed the performance and efficiency of the EV's powertrain, affecting acceleration time, top speed, available torque at the wheels and energy consumption. Indeed, the narrow output speed range obtained with this design in comparison to the torque required to start the vehicle demonstrated the importance of a variable transmission.

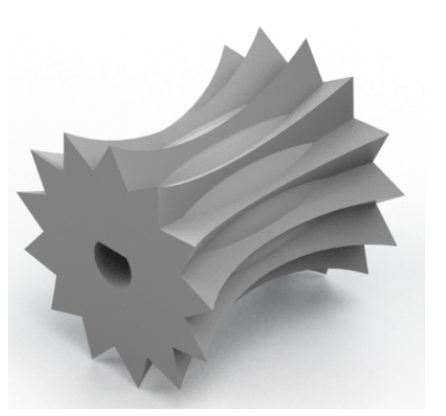

(a)

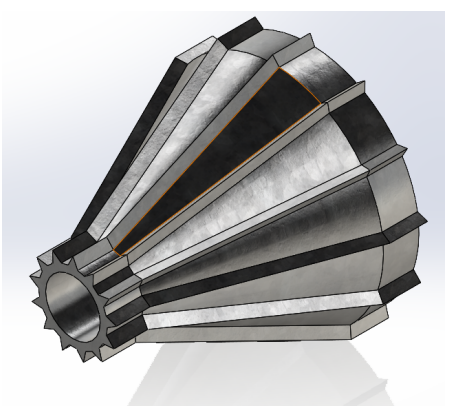

(b)

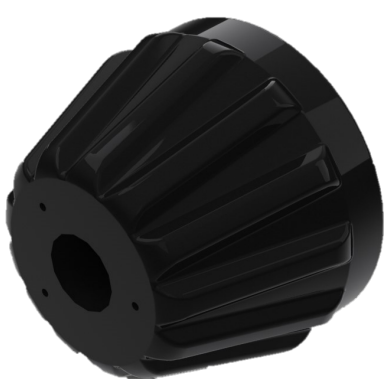

(c)

Figure 2. Gear design concepts: (a) first gear attempt, (b) idealized conic gear and (c) final gear.

The simplest implementation of a variable transmission system began with an idealized conic gear, as illustrated in Figure $2 b$. This component was originally believed to be assembled in the motor axle and directly coupled to the vehicle's rear tire. If the electric motor was assembled with the proper inclination angle and on a movable platform, the conical shape would allow the gear diameter in contact with the tire to gradually increase. As a result, the solution was to mount the motor on a board with linear bearings, allowing the speed ratio to be varied by lateral movement of the board. To move the motor base and thus the gear, a system of strings and pulleys connected to a lever system can be attached to the board. When necessary, the pilot may pull or push this lever, thereby changing the speed ratio. The first conic gear designed, shown in Figure $2 b$, was able to achieve the proposed speed range. However, its geometric format was not properly designed to handle the contact force with the vehicle rear tire, resulting in teeth fractures, wear and loss of performance. The EV prototype and idealized variable transmission concept employing the final gear design in Figure $2 \mathrm{c}$ is shown in Figure 3.

The maximum and minimum gear speed ratios $u$ from the variable transmission can be obtained considering the wheel tire diameter $D$ and the maximum and minimum values of the conic gear diameter $d$, given by

$$
\max u=\frac{D}{\min d} \quad \text { and } \quad \min u=\frac{D}{\max d} .
$$

The vehicle speed $V_{x}$ as a function of the gear ratio $u$ and angular velocity of the electric motor $\omega=2 \pi n / 60$, where $n$ is the rotating velocity of the electric motor in rpm, from which the limiting EV speeds can be determined, is given by 


$$
V_{x}=\frac{\omega D}{2 u} .
$$

Similar relations can be established to determine torque magnification at the wheel. The corresponding torques at the wheel and gear, $T_{D}$ and $T_{d}$, respectively, can be determined according to the rated power of the motor $P$ and the transmission efficiency $\eta$, yielding

$$
T_{d}=\frac{P}{\omega} \quad \text { and } \quad T_{D}=u \eta T_{d} .
$$
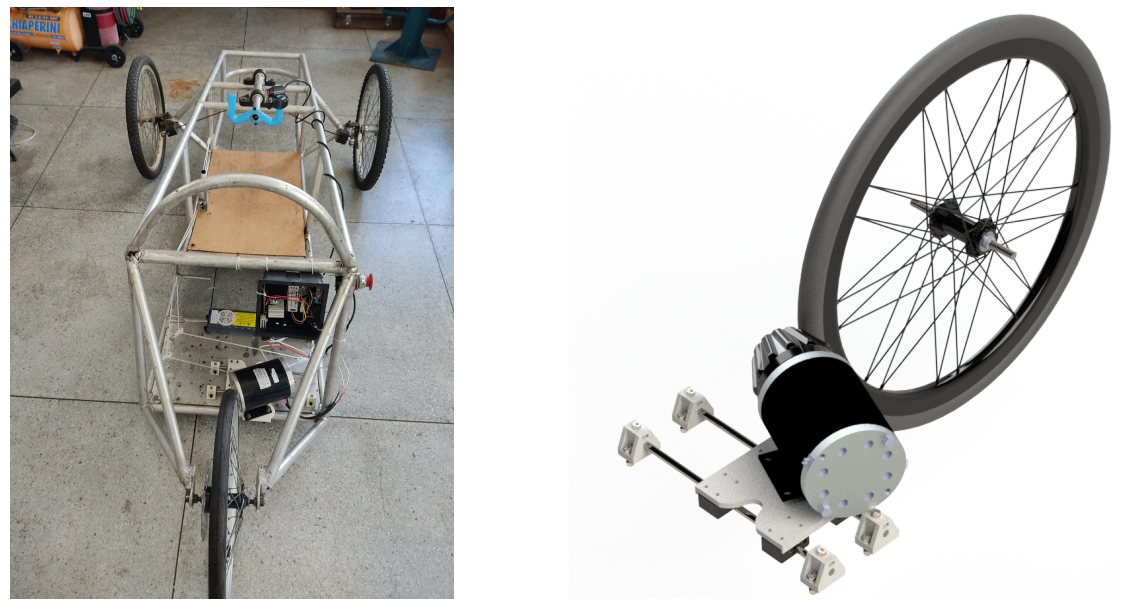

Figure 3. EV prototype (left) and virtual representation of the idealized CVT concept (right).

As previously stated, the final gear design depicted in Figure $2 \mathrm{c}$ was prototyped using polymer additive manufacturing (AM) technologies. These involve layering materials to create objects from 3D model data via material extrusion in which the material is selectively dispensed through a nozzle or orifice. The process is called FDM (fused deposition modeling; a trademark of the company Stratasys), and it is a material extrusion process that uses heated extrusion and layer deposition of materials to create thermoplastic parts. In its untrademarked form, the FDM process is also referred to as FFF (fused filament fabrication), and is typically associated with a less industrial grade technology (desktop, hobbyist level 3D printing technology). The 3D printer model used is the widely accessible, low-cost and hobbyist grade technology, Anet A8. To determine the optimal printing parameters for the STL part file generated from the 3D geometric model of the gear, a commercially available plug-in and tool called SmartSlice was used. It is designed to be used with Ultimaker's Cura slicer software and incorporates an optimization algorithm. To ensure structural requirements are met, the software is fed with the force acting on the component, the component's maximum displacement and the desired safety factor. Additionally, this plug-in makes use of modifier meshes to reinforce infill density in critical regions without requiring the entire body to be reinforced with additional material.

\section{Results and Discussion}

Considering an intermediary value of motor speed $n=1900 \mathrm{rpm}$ and the wheel diameter $D=480 \mathrm{~mm}$, it is possible to estimate the conic gear's maximum and minimum diameters according to Equations (1)-(3). The minimum and maximum gear diameters chosen were $\min d=68.71 \mathrm{~mm}$ and $\max d=96.19 \mathrm{~mm}$ and the corresponding gear speed ratios found were $\max u=6.99: 1$ and $\min u=4.99: 1$, respectively. For simplicity, adopting $100 \%$ transmission efficiency, the variation of the vehicle's speed and wheel torque as a function of the gear diameter can be estimated. To gain a better understanding of the forces and torques acting on the vehicle powertrain and to evaluate the proposed CVT, a computational dynamic vehicle model of the EV prototype was implemented in MATLAB/Simulink but is not shown here due to space constraints. 
PETG (polyethylene terephthalate glycol) was chosen as the material for the second version of the gear. Table 1 compares the mechanical properties of PETG to those of some of the most commonly used filaments in 3D printing from the 3Dlab brand. Although PLA (polylactic acid) is stronger than PETG, PETG is better suited for outdoor use due to its resistance to weather and sunlight. PETG has a temperature tolerance of approximately $75^{\circ} \mathrm{C}$. On the other hand, 3D printed parts made of PLA must be kept below $55^{\circ} \mathrm{C}$ to avoid thermal deformation and stiffness relaxation.

Table 1. Typical material properties values of common filament materials for 3D printing.

\begin{tabular}{lccc}
\hline Properties & ABS & PLA & PETG \\
\hline Tensile modulus $(\mathrm{MPa})$ & 1335 & 1896 & 1067 \\
Yield strength $(\mathrm{MPa})$ & 14.7 & 24.8 & 18.6 \\
Ultimate strength $(\mathrm{MPa})$ & 29 & 46 & 32.6 \\
Strain at break $(\%)$ & 7.08 & 3.69 & 7.74 \\
Melting point $\left({ }^{\circ} \mathrm{C}\right)$ & 220 & 185 & 240 \\
Specific weight $\left(\mathrm{g} / \mathrm{cm}^{3}\right)$ & 1.04 & 1.24 & 1.27 \\
\hline
\end{tabular}

The input data used to analyze the gear printing process are shown in Table 2. The safety factor was defined as 1.5 and maximum displacement on the gear teeth flanks to an applied distributed force was considered equal to $0.3 \mathrm{~mm}$. The total load force distributed on the teeth flanks was equal to $621.78 \mathrm{~N}$ and was obtained considering the maximum traction force and the respective gear ratio discussed in the previous section. As shown in Table 2, by adjusting the printing parameters to its optimized setting it was possible to reduce the mass from 437.2 to $386.7 \mathrm{~g}$, maintaining an acceptable maximum displacement and guaranteeing the safety factor previously stipulated. Figure 4 illustrates the gear slicing process before and after optimization. In Figure 4 , it is possible to verify the mesh reinforcement close to the teeth surface. Moreover, local reinforcements were used in the part holes. Due to local reinforcement complexity, the printing time in the optimized configuration was approximately $40 \mathrm{~min}$ higher; however, it is not critical in this project since the main concern is about improving the gear mechanical strength and stiffness.

Table 2. Three-dimensional printing optimization parameters and comparison of results.

\begin{tabular}{|c|c|c|c|c|}
\hline \multirow{2}{*}{ Parameters } & \multicolumn{2}{|r|}{ Initial Settings } & \multicolumn{2}{|c|}{ Optimized Settings } \\
\hline & Extruder & Local Reinforcements & Extruder & Local Reinforcements \\
\hline Top and bottom layers & 3 & - & 4 & 3 \\
\hline Infill density (\%) & 100 & - & 35 & 85 \\
\hline Wall thickness (mm) & 0.6 & - & 0.6 & 0.6 \\
\hline Wall line counting & 3 & - & 2 & 3 \\
\hline \multicolumn{5}{|l|}{ Results } \\
\hline Mass (g) & \multicolumn{2}{|r|}{437.2} & \multicolumn{2}{|r|}{386.7} \\
\hline Max displacement (mm) & \multicolumn{2}{|r|}{0.24} & \multicolumn{2}{|r|}{0.28} \\
\hline Printing time & \multicolumn{2}{|r|}{$22 \mathrm{~h} 57 \mathrm{~min}$} & \multicolumn{2}{|r|}{$23 \mathrm{~h} 36 \mathrm{~min}$} \\
\hline Factor of safety & \multicolumn{2}{|r|}{3.92} & \multicolumn{2}{|r|}{3.24} \\
\hline
\end{tabular}



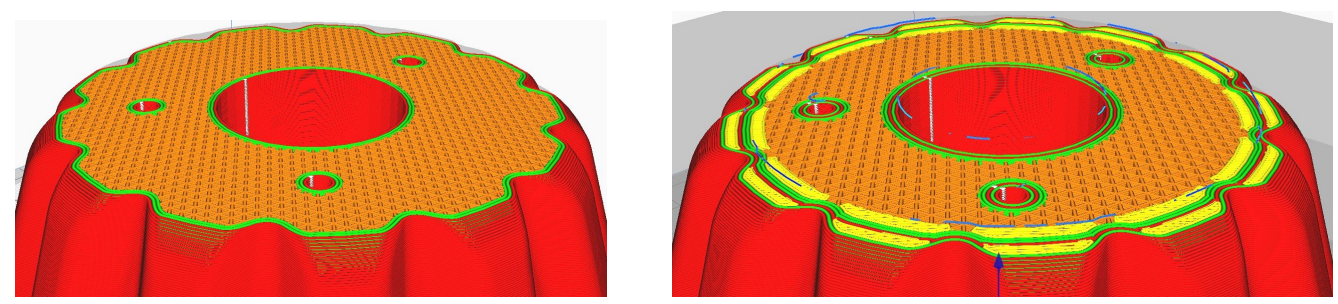

Figure 4. A 3D printed gear slicing comparison: initial (left) and optimized slicing (right) performed with the 3D printing software Cura slicer from Ultimaker. The red lines denote external shell surface; orange, the infill region; and green, the inner wall.

\section{Conclusions}

The present work proposes a new CVT architecture utilizing a conic gear. This gear engages with the rear wheel's tire and is coupled to the electric motor axle. The speed ratio change is obtained moving the motor, which is mounted over a movable board with linear bearings. The proposed variable transmission is unprecedented and its constructive simplicity suggests opportunities for application in small vehicles. A computational model was implemented to simulate a prototype three-wheeled vehicle with this designed transmission. Furthermore, an optimization algorithm was used to obtain optimized printing parameters for manufacturing the gear in PETG. The obtained set of parameters demonstrated possibilities to reduce the gear mass about $12 \%$ in relation to the 3D-printed gear with $100 \%$ of material infill without losing mechanical resistance and stiffness. In future work, the EV prototype will be tuned and tested in a real-driving cycle. To determine the powertrain's efficiency, data on speed, time, motor current, battery voltage and battery consumption will be collected. Additional testing will be conducted to determine the transmission's efficiency and durability.

Author Contributions: Conceptualization, all; methodology, all; software, M.R.C.C. and T.P.B.; validation, M.R.C.C. and T.P.B.; formal analysis, all; investigation, all; writing-original draft preparation, M.R.C.C. and C.M.A.V.; writing-review and editing, T.P.B. and C.M.A.V.; funding acquisition, T.P.B. and C.M.A.V. All authors have read and agreed to the published version of the manuscript.

Funding: The first two authors gratefully acknowledge that this study was funded, in part, by the National Council for Scientific and Technological Development (CNPq), as well as the support provided by the Center of Innovation, Research and Teaching of Mechatronics (NIPEM) and by the Federal University of São João del-Rei (UFSJ). The third author gratefully acknowledges the support provided by the Foundation for Science and Technology (FCT) of Portugal, within the scope of the project of the Research Unit on Materials, Energy and Environment for Sustainability (proMetheus), Ref. UID/05975/2020, financed by national funds through the FCT/MCTES.

Institutional Review Board Statement: Not applicable.

Informed Consent Statement: Not applicable.

Data Availability Statement: Not applicable.

Conflicts of Interest: The authors declare no conflict of interest.

\section{References}

1. Reddy, K.J.; Natarajan, S. Energy sources and multi-input DC-DC converters used in hybrid electric vehicle applications-A review. Int. J. Hydrogen Energy 2018, 43, 17387-17408. [CrossRef]

2. Miyamoto, M.; Takeuchi, K. Climate agreement and technology diffusion: Impact of the Kyoto Protocol on international patent applications for renewable energy technologies. Energy Policy 2019, 129, 1331-1338. [CrossRef]

3. Alnunu, N.; Said, S.; Al-Sharman, S.; Al-Ibrahimi, A.; AbdulAziz, A.; Hellabi, M.A.; Touati, F.; Ghani, S.; Mahdi, E.S.; Benammar, M. Design of Qatar University's first solar car for Shell Eco-Marathon competition. In Proceedings of the 2012 First International Conference on Renewable Energies and Vehicular Technology, Nabeul, Tunisia, 26-28 March 2012; pp. 49-54. [CrossRef]

4. Baldissera, P.; Delprete, C. Human powered vehicle design: A challenge for engineering Education. In Proceedings of the ASME 2014 12th Biennial Conference on Engineering Systems Design and Analysis (ESDA2014), Copenhagen, Denmark, 25-27 July 2014. [CrossRef] 
5. Buck, L.; Mclening, C.; Burgess, J. Eco-car: A perfect vehicle for technical design teaching? In Proceedings of the 16th International Conference on Engineering and Product Design Education (E\&PDE14), Design Education and Human Technology Relations, University of Twente, Enschede, The Netherlands, 4-5 September 2014.

6. Abdulwahed, M.; Ahmad, S.; Hasna, M.O.; Ghani, S.; Benammar, M. Contribution of Shell Eco-Marathon engineering design experience to soft skills development: A qualitative analysis in the Asian context. In Proceedings of the 2014 International Conference on Interactive Collaborative Learning (ICL), Dubai, United Arab Emirates, 3-6 December 2014. [CrossRef]

7. Von Solms, S.; Nel, H. Reflective learning in engineering education: A case study of shell Eco-Marathon. In Proceedings of the 2017 IEEE International Conference on Industrial Engineering and Engineering Management (IEEM), Singapore, 10-13 December 2017. [CrossRef]

8. Verma, A.R.; Chaurasia, A.; Jaiswal, S.S.; Bhonde, L.; Guha, R.; Sahu, H.; Patel, S.; Banthiya, S.; Maddeshiya, S.; Mirzapure, S.; et al. Team AVERERA's Alterno V4.0-A hyper energy-efficient electric prototype vehicle for Shell Eco-Marathon. SAE Tech. Pap. 2021. [CrossRef]

9. Ary, A.K.; Sanjaya, Y.; Prabowo, A.R.; Imaduddin, F.; Nordin, N.A.B.; Istanto, I.; Cho, J.H. Numerical estimation of the torsional stiffness characteristics on urban Shell Eco-Marathon (SEM) vehicle design. Curved Layer Struct. 2021, 8, 167-180. [CrossRef]

10. Stabile, P.; Ballo, F.; Mastinu, G.; Gobbi, M. An ultra-efficient lightweight electric vehicle-Power demand analysis to enable lightweight construction. Energies 2021, 14, 766. [CrossRef]

11. Carello, M.; Pinheiro, H.C.; Longega, L.; Di Napoli, L. Design and modelling of the powertrain of a hybrid fuel cell electric vehicle. SAE Tech. Pap. 2021. [CrossRef]

12. Sethi, N.; Chauhan, P.; Bansal, S.; Singari, R.M. Robust vehicle development for student competitions using fiber-reinforced composites. In Lecture Notes in Mechanical Engineering; Springer: Singapore, 2021; pp. 61-76. [CrossRef]

13. Gilewski, M.; Czarnigowski, J.; Górski, W.; Mitrus, K.; Różyło, P.; Trocha, S.; Wypychowski, M. Strength analysis of the drive wheel hub of a hydrogen-powered prototype hyper-light vehicle. J. Phys. Conf. Ser. 2021, 1736, 012056. [CrossRef]

14. Kılıç, A.E. Redesign of Drivetrain Component of a Shell Eco-Marathon Vehicle for Additive Manufacturing via Topology Optimization. Master's Thesis, Piri Reis Üniversitesi, Istanbul, Turkey, 2020.

15. Vaughan, N. Transmission and Driveline: Introduction. In Encyclopedia of Automotive Engineering; Crolla, D., Foster, D., Kobayashi, T., Vaughan, N., Eds.; Wiley: Hoboken, NJ, USA, 2014; p. 11. [CrossRef]

16. Attaran, M. The rise of 3-D printing: The advantages of additive manufacturing over traditional manufacturing. Bus. Horizons 2017, 60, 677-688. [CrossRef]

17. Agapovichev, A.V.; Balaykin, A.V.; Smelov, V.G. Production technology of the internal combustion engine crankcase using additive technologies. Mod. Appl. Sci. 2015, 9, 335-343. [CrossRef]

18. Gray, J.; Depcik, C. Review of additive manufacturing for internal combustion engine components. SAE Int. J. Eng. 2020, 13, 617-632. [CrossRef]

19. Ehsani, M.; Gao, Y.; Longo, S.; Ebrahimi, K.M. Modern Electric, Hybrid Electric, and Fuel Cell Vehicles, 3rd ed.; CRC Press: Boca Raton, FL, USA, 2018. [CrossRef] 